\title{
Effectiveness of geriatric rehabilitative care after fractures of the proximal femur in elderly women: a randomised clinical trial
}

\author{
David C Kennie, John Reid, Ian R Richardson, A A Kiamari, Christine Kelt
}

\begin{abstract}
Objective-To compare postoperative collaborative care between orthopaedic surgeons and physicians in geriatric medicine with routine orthopaedic care in elderly women with proximal femoral fracture.
\end{abstract}

Design-Exclusion of patients dying before fit enough to enter trial, those with pathological fractures, those likely to be discharged within seven days of entering the trial, and those remaining unfit for transfer to a peripheral hospital. Remainder allocated to two groups: treatment group and control group.

Setting-District hospital acute admission ward and rehabilitation ward.

Patients -144 sequentially admitted elderly women with proximal fracture of the femur; 36 excluded on above criteria and remainder entered into trial.

Intervention-Both treatment and control groups ( $n=54$ in each) received physiotherapy and other services. The treatment group also received thrice weekly supervision by a geriatrician.

End points-Physical independence, residence after discharge, and length of hospital stay.

Measurements and main results-At discharge significantly more patients in treatment group were independent in terms of activities of daily living than controls (41 $v 25$ ) and their median stay was 24 days (range 8-197) compared with 41 (9-365) (95\% confidence intervals for difference 2 to 25 ). Significantly fewer treatment patients were discharged to institutional care $(10 \% v 32 \%$; $95 \%$ confidence interval for difference $6 \%$ to $37 \%$ ) and more to their own homes $(63 \% v 38 \%$; $95 \%$ confidence interval for difference $6 \%$ to $44 \%$ ). These beneficial effects were consistent across a range of ages and mental states.

Conclusions-Both hospital and patient benefited when postoperative rehabilitation was provided in a setting specialising in such care for elderly patients with trauma.

Department of Geriatric Medicine, Royal Infirmary, Stirling FK8 2AU

David C Kennie, FRCP, consultant physician John Reid, MRCP, consultant physician

Ian R Richardson, MB, medical officer

A A Kiamari, MRCP, locum associate specialist

Christine Kelt, MRCGP, registrar

Correspondence to: $\mathrm{Dr}$ Kennie. to age. ${ }^{35-9}$ Effective prevention in old age is difficult. Not only is the underlying osteoporosis irreversible by current treatments but the patient's postural instability is a major causal factor. ${ }^{1011}$
In response to this growing and unpreventable problem several groups of orthopaedic surgeons and physicians in geriatric medicine have collaborated in the care of these patients. ${ }^{42-20}$ The more successful studies that have been reported suggest that collaborative care shortens hospital stay. Most of these studies have been descriptive or have used retrospective controls. Our prospective randomised study of collaborative care aimed at determining whether postoperative management by a physician in geriatric medicine could shorten hospital stay, improve personal independence at discharge, reduce the level of care needed after discharge, and do these without increasing morbidity and mortality.

\section{Patients and methods}

A pilot study suggested that changes in the chosen measures of outcome (except length of inpatient stay) would be significant at $\mathrm{p}<0.05$ with a power of 0.80 if 100 patients were studied. We proceeded on this basis even though the variance of length of stay, which in the pilot study was large even after logarithmic transformation, might prevent a real difference being shown. Approval for the study was given by the local ethical committee.

The orthopaedic unit taking part in the study served a mixed urban and rural population of about 128000 . Over 18 months every woman aged 65 and over who had fractured the proximal femur was assessed after operation by a senior doctor in the department of geriatric medicine. Of 144 patients seen, 36 were excluded by predetermined criteria: $(a)$ they died before becoming fit enough to enter the trial $(n=8) ;(b)$ they had pathological fractures $(n=5) ;(c)$ they were likely to be discharged within seven days of entering the trial $(n=14$; in these cases most of the fractures occurred in a nursing home or ward to which the patients would return for further nursing a few days after internal fixation); or $(d)$ they remained unfit for transfer by ambulance to a peripheral hospital $(n=9$; most of these patients needed prolonged traction or other. short term specialist care at the district general hospital).

When the orthopaedic surgeon judged them fit to be moved to a rehabilitation ward the remaining patients were allocated to either a treatment or a control group in a predetermined random sequence. The control group $(n=54)$ generally remained in the orthopaedic admission ward, a few of these patients being moved into other short stay wards at the discretion of the consultant orthopaedic surgeon. These patients received regular attention on orthopaedic ward rounds, and the demand for beds encouraged their early discharge. The treatment group $(n=54)$ was transferred by ambulance $5 \mathrm{~km}$ to orthopaedic beds in a peripheral hospital. The median delay between entry 
into the study and transfer was one day (range $0-7$ ). A general practitioner provided their day to day medical attention, and a consultant physician in geriatric medicine attended two ward rounds and one conference of the multidisciplinary team each week. An orthopaedic specialist was not routinely present, but

TABLE I-Residence before admission, social and physical dependence, and physical and mental state at entry into study of 108 elderly women with fractures of proximal femur

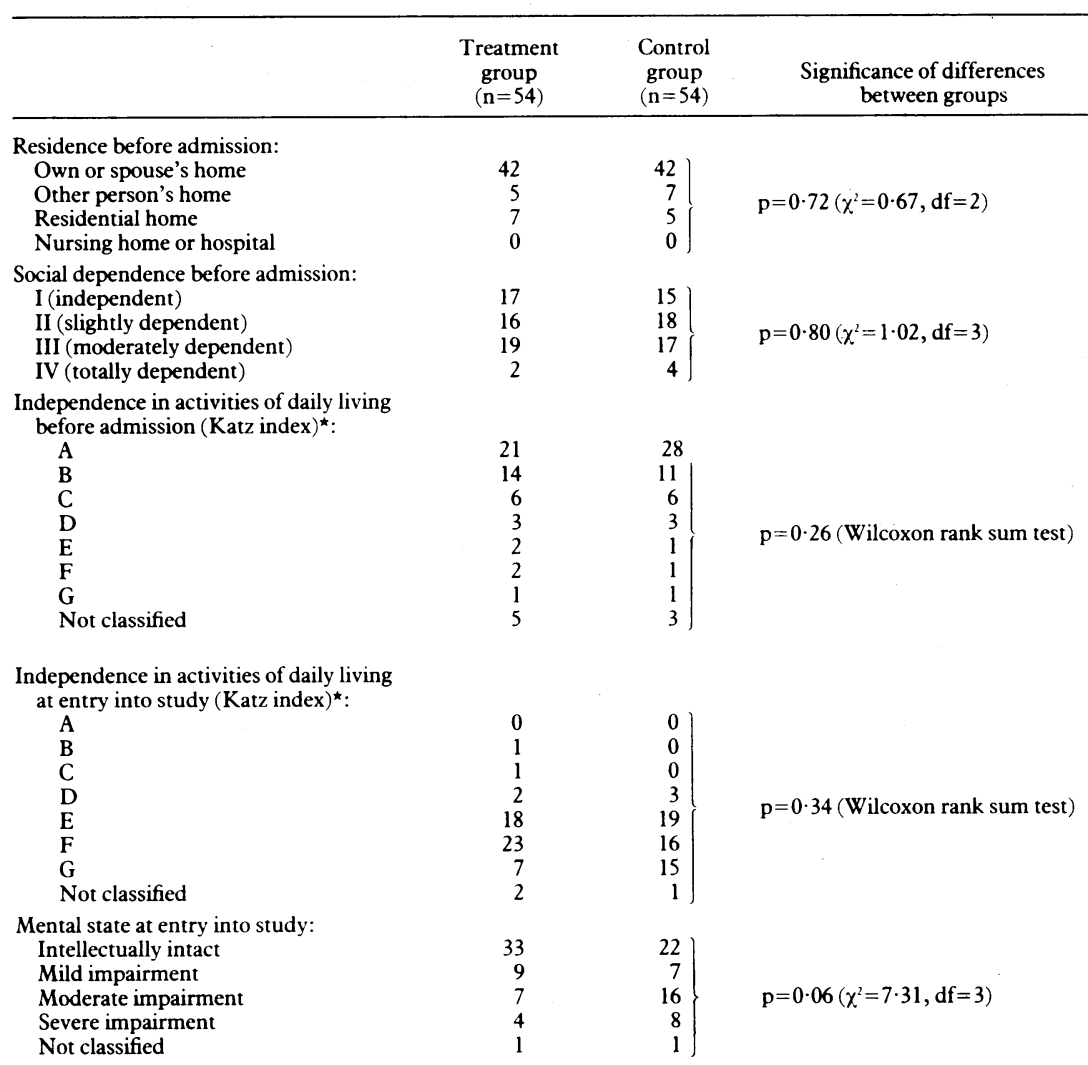

* $\mathrm{A}=$ Independent in feeding, continence, transferring, going to toilet, dressing and bathing; $\mathrm{B}=$ independent in all but one of these functions; $\mathrm{C}=$ independent in all but bathing and one additional function; $\mathrm{D}=$ independent in all but bathing, dressing, and one additional function; $\mathrm{E}=$ independent in all but bathing, dressing, going to toilet, and one additional function; $\mathrm{F}$ =independent in all but bathing, dressing, going to toilet, transferring, and one additional function; $G=$ dependent in all six functions; Not classified=dependent in at least two functions but not classifiable as $\mathrm{C}, \mathrm{D}, \mathrm{E}$, or $\mathrm{F}$. TABLE III-Length of inpatient fracture of proximal femur

\begin{tabular}{lcc}
\hline & $\begin{array}{c}\text { Treatment } \\
\text { group } \\
(\mathbf{n}=54)\end{array}$ & $\begin{array}{c}\text { Control } \\
\text { group } \\
(\mathbf{n}=54)\end{array}$ \\
\hline \$1 Week & 0 & 0 \\
-4 Weeks & 32 & 18 \\
-3 Months & 18 & 28 \\
$>3$ Months & 4 & 8 \\
\hline
\end{tabular}

TABLE II - Details of fracture and operation of 108 elderly women with fractures of proximal femur

\begin{tabular}{lcc}
\hline & $\begin{array}{c}\text { Treatment } \\
\text { group } \\
(\mathbf{n}=54)\end{array}$ & $\begin{array}{c}\text { Control } \\
\text { group } \\
(\mathbf{n}=54)\end{array}$ \\
\hline Type of fracture: & & \\
Intracapsular & 25 & 28 \\
Extracapsular & 29 & 26 \\
Type of operation: & 21 & 24 \\
$\quad$ Hemiarthroplasty & 21 & 25 \\
Dynamic hip screw & 12 & 5 \\
All others & 16 & 10 \\
Type of anaesthetic: & 38 & 44 \\
Spinal & & \\
General & 41 & 39 \\
Prophylactic antibiotics given: & 13 & 15 \\
Yes & & \\
No & 0 & 0 \\
Anticoagulants given: & 54 & 54 \\
Yes & 54 \\
No & & \\
\hline
\end{tabular}

advice was available on demand. Six beds were adequate for these patients and could also accommodate a small number of elderly patients with other types of fracture. Both treatment and control groups received physiotherapy, occupational therapy, and orthotic and other services. No attempt was made to blind either staff or patients to the fact that the trial was being conducted, and no patient was excluded on grounds of non-compliance.

Dates of the fracture, admission to hospital, operation, entry into the study, and discharge from orthopaedic inpatient care were recorded, as were the patient's residence before admission and after discharge, the site of the fracture, the nature of the operation and perioperative treatment, and (when relevant) death. The Katz index of independence in the activities of daily living was used to measure physical functioning before admission (retrospectively), at entry into the study, and at discharge. ${ }^{21}$. The short portable mental state questionnaire was used to measure mental state at entry into the study and at discharge from orthopaedic inpatient care. ${ }^{22}$ Dependence on social support services before admission was estimated by classifying the patient into one of four groups. ${ }^{23}$ (These groups indicate the prognosis after hip fractures.) Assessments of independence in the activities of daily living were made jointly by an occupational therapist and a physiotherapist, and all other assessments were made by a doctor. Regular meetings of the assessors were held to ensure consistent assessment throughout the study.

Patients were allocated in random sequence determined before the start of the study after the method of Tukey. ${ }^{24}$ The allocation was in sealed envelopes held by a departmental secretary. Data analysis was primarily descriptive, and either the Wilcoxon rank sum test or the $\chi^{2}$ test was used to compare groups. Two tailed tests were used to determine probability values.

\section{Results}

Before admission to hospital and at entry into the study the groups were similar in their type of residence and social and physical dependence, though randomisation may have introduced a small difference in mental state between the groups (table I). The median ages in the treatment and control groups were 79 (range $65-94)$ and 84 (66-94) respectively (95\% confidence interval for difference -1 to 7$)$. The two groups had similar types of fractures and operation and did not differ significantly in the interval from fracture to operation (median 1 day (0-15) in the treatment group and $1(0-21)$ in the control group; $95 \%$ confidence interval for difference -1 to 1 ) or from operation to entry into the study (median 3.5 days (1-32) in the treatment group and 4 (1-35) in the control group; $95 \%$ confidence interval for difference -1 to 2 ). Physical independence on discharge was significantly better in the treatment than the control group. More patients in the treatment group (41 $v 25)$ were in the more functional categories for independence in the activities of daily living (B-D) and significantly more patients from the control group (19v6) in the dependent

TABLE IV-Influence of age on outcome in 108 elderly women with fracture of proximal femur (54 treated in geriatric rehabilitation facility compared with 54 treated in acute admission wards (controls))

\begin{tabular}{|c|c|c|c|c|c|c|c|c|}
\hline & \multicolumn{2}{|c|}{ Age $<75$} & \multicolumn{2}{|c|}{ Age 75-79 } & \multicolumn{2}{|c|}{ Age 80-84 } & \multicolumn{2}{|c|}{ Age $\geqslant 85$} \\
\hline & $\begin{array}{l}\text { Treatment } \\
\text { group }\end{array}$ & $\begin{array}{l}\text { Control } \\
\text { group }\end{array}$ & $\begin{array}{l}\text { Treatment } \\
\text { group }\end{array}$ & $\begin{array}{l}\text { Control } \\
\text { group }\end{array}$ & $\begin{array}{l}\text { Treatment } \\
\text { group }\end{array}$ & $\begin{array}{l}\text { Control } \\
\text { group }\end{array}$ & $\begin{array}{c}\text { Treatment } \\
\text { group }\end{array}$ & $\begin{array}{l}\text { Control } \\
\text { group }\end{array}$ \\
\hline Median length of stay in hospital (days) & 19 & 24.5 & 23 & 39 & 24 & $30 \cdot 5$ & 39 & 59 \\
\hline $\begin{array}{l}\text { Katz index of independence in activities } \\
\text { of daily living at discharge } \\
\text { Type of residence after discharge }\end{array}$ & $\begin{array}{c}\text { B } \\
\text { Own home }\end{array}$ & $\begin{array}{c}\text { C } \\
\text { Own home }\end{array}$ & $\begin{array}{c}\text { B/C } \\
\text { Own home }\end{array}$ & $\frac{E}{\text { Residential home }}$ & $\begin{array}{c}C \\
\text { Own home }\end{array}$ & $\begin{array}{c}\mathrm{D} \\
\text { Other home }\end{array}$ & $\begin{array}{c}\mathrm{D} / \mathrm{E} \\
\text { Residential home }\end{array}$ & $\frac{\mathbf{E}}{\text { Residential home }}$ \\
\hline
\end{tabular}

${ }^{\star}$ Categories containing the median patient; for definition of categories see footnote to table I. 


\begin{tabular}{|c|c|c|c|c|c|c|c|c|}
\hline \multirow[b]{2}{*}{. } & \multicolumn{2}{|c|}{ Intellectually intact } & \multicolumn{2}{|c|}{ Mild impairment } & \multicolumn{2}{|c|}{ Moderate impairment } & \multicolumn{2}{|c|}{ Severe impairment } \\
\hline & $\begin{array}{l}\text { Treatment } \\
\text { group }\end{array}$ & $\begin{array}{l}\text { Control } \\
\text { group }\end{array}$ & $\begin{array}{l}\text { Treatment } \\
\text { group }\end{array}$ & $\begin{array}{l}\text { Control } \\
\text { group }\end{array}$ & $\begin{array}{l}\text { Treatment } \\
\text { group }\end{array}$ & $\begin{array}{l}\text { Control } \\
\text { group }\end{array}$ & $\begin{array}{l}\text { Treatment } \\
\text { group }\end{array}$ & $\begin{array}{l}\text { Control } \\
\text { group }\end{array}$ \\
\hline $\begin{array}{l}\text { Median length of stay in hospital (days) } \\
\text { Katz index of independence in activities }\end{array}$ & 21 & 31 & 25 & 31 & 21 & 61 & 53 & 66 \\
\hline $\begin{array}{l}\text { of daily living at discharge } \\
\text { Type of residence after discharge }\end{array}$ & $\begin{array}{c}\mathrm{C} \\
\text { Own home }\end{array}$ & $\begin{array}{c}\mathrm{C} \\
\text { Own home }\end{array}$ & $\begin{array}{c}\mathrm{D} \\
\text { Own home }\end{array}$ & $\begin{array}{c}\mathrm{D} \\
\text { Residential home }\end{array}$ & $\begin{array}{c}\mathrm{D} \\
\text { Other home }\end{array}$ & $\begin{array}{c}E / F \\
\text { Nursing home }\end{array}$ & $\begin{array}{c}\mathrm{E} / \mathrm{F} \\
\text { Residential home }\end{array}$ & $\stackrel{\text { G }}{\text { Nursing home }}$ \\
\hline
\end{tabular}

*Categories containing the median patient; for definition of categories see footnote to table $\mathrm{I}$.

categories $(E-G)(p=0.005)$. Not unexpectedly, this improved functioning was accompanied by shorter hospital stays (table III). The median stay in the treatment group was 24 days (8-197) compared with 41 days $(9-365)$ in the control group $(95 \%$ confidence interval for difference 2 to 25 days). The greater independence led to significantly fewer discharges of patients in the treatment group to NHS or private nursing care (5 $v 16)$ and more to patients' own homes (31 $v 19)(\mathbf{p}=0.03)$. Subgroup analysis showed that the beneficial effects of treatment on physical independence, residence after discharge, and length of hospital stay were consistent across a range of ages and mental states (tables IV and V).

\section{Discussion}

Although there are numerous reports of rehabilitative care for elderly patients with hip fractures, most have used only historical controls. It is difficult to draw conclusions from such data as operative and anaesthetic practices may change over time. Likewise the availability of beds often changes, thus influencing outcome. Other trials have chosen to rehabilitate patients with moderate disability but have not described their criteria. ${ }^{15} 1825$ Although most reports indicate benefit from care by specialists in geriatric medicine, two studies failed to show significant differences compared with conventional management. ${ }^{15} 19$ One of these studies had small numbers of patients and long delays in transfer to a joint care facility. ${ }^{19}$

Our study was undertaken to reach a clear conclusion about the impact of collaborative care on the length of hospital stay. It has been suggested that within the limited resources of the NHS the blockage of beds by elderly patients with orthopaedic trauma is at least partly responsible for the long waiting times for elective hip surgery. ${ }^{26}$ Although this is contested, the potential for improvement is considerable. Robbins and Donaldson analysed the numbers of patients in hospital at each stage of care and found that $51 \%$ were recovering from operations without complications and $28 \%$ were continuing to stay in hospital after medical and surgical care was complete. ${ }^{27}$

Rehabilitation led by a geriatrician clearly benefited the elderly women in our study. Several possibilities may explain these results. It was difficult to compare the amount of physiotherapy given to the two groups and the group receiving rehabilitation may have had more physiotherapy, though the number of sessions that this frail aged population could sustain each day made the total differ only slightly from that received by the control group. Of equal importance was the greater ability of the nurses to conduct functionally orientated care when working outside the acute orthopaedic ward with its emphasis on caring for highly dependent patients. Such rehabilitation requires a reversal of the traditional caring role so that nurses encourage patients to do things for themselves; this is similar to Orem's self care deficit theory of nursing practice. ${ }^{28} \mathrm{~A}$ further possible explanation for our results was the input from the consultant geriatrician, who, in the role of case manager, may have sustained a greater interest in the circumstances of patients' discharge, used community resources more fully, and been more willing than an orthopaedic surgeon to take calculated risks when discharging frail elderly patients back to the community.

Although the results for the patients who received rehabilitative aftercare were better than for the patients who received conventional management, they should not be considered optimal. There are many components in the management of elderly patients with hip fractures, and additional benefits might have resulted from changes in operative style and practice, ${ }^{25} 29$ greater use of spinal anaesthesia, ${ }^{30}$ and use of antibiotics around the time of operation ${ }^{31}$ and anticoagulation, ${ }^{32}$ all of which are potentially beneficial. Community services focused on particular groups of patients may also accelerate discharge from hospital. ${ }^{25}$

We did not attempt to cost the two types of care, but in a similar study Fordham et al found the cost of geriatric-orthopaedic management in 1985 to be $£ 93$ more per patient than ordinary orthopaedic management. ${ }^{19}$ They found no difference in the lengths of hospital stay between the two groups, and much of the additional cost was in the servicing of and transport to a peripheral hospital unit. The cost benefit of this type of collaborative care is therefore still unknown. Savings are unlikely within the current funding structure of the NHS as a vacant bed is likely to be filled immediately.

This trial confirms the effectiveness of geriatric rehabilitative aftercare for elderly women with hip fractures. Hospital stay was reduced, and, more importantly, functional independence and the likelihood of returning to an independent life were improved. Without provision of rehabilitative aftercare such patients will occupy an ever increasing proportion of hospital beds.

We thank Mrs K Park, occupational therapist, and Mrs A Burns, physiotherapist, for carrying out the functional assessments; Dr H Gilmour for guidance on the design of the study; Mr T S Kerr and colleagues for their collaboration; and Mrs I Anderson for secretarial support. This project was funded by the Forth Valley Health Board.

1 Wild W, Nayak USL, Isaacs B. How dangerous are falls in old people at home? BrMed F 1981;282:266-8.

2 D'Arcy J, Devas MB. Treatment of fractures of the femoral neck by replacement with the Thomson prosthesis. F Bone foint Surg [Br] 1976; 58:279-86.

3 Gallanaugh SC, Martin A, Millard PH. Regional survey of femoral neck fractures. Br Med f 1976;ii:1496-7.

4 Thomas TG, Stevens RS. Social effects of fractures of the neck of the femur. BrMed F 1974;iii:456-8.

5 Baker MR. An investigation into secular trends in the incidence of femoral neck fracture using hospital activity analysis. Public Health 1980;94:368-74.

6 Lewis AF. Fracture of the neck of femur: changing incidence. $\mathrm{Br} \mathrm{Med} \mathcal{F}$ 1981;283:1217-20.

7 Wallace WA. The increasing incidence of fractures of the proximal femur: an orthopaedic epidemic. Lancet 1983;i:1413-4.

8 Boyce WJ, Vessey MP. Rising incidence of fracture of the proximal femur. Lancet 1985;i:150-1.

9 Currie AL, Reid DM, Brown N, Nuki G. An epidemiological study of fracture of the neck of femur. Health Bull (Edinb) 1986;44:143-8.

10 Aitken JM. Relevance of osteoporosis in women with fracture of the femoral neck. BrMed f 1984;288:597-601.

11 Cooper C, Barker DJP, Morris J, Briggs RSJ. Osteoporosis, falls, and age in fracture of the proximal femur. BrMed $\mathcal{F}$ 1987;295:13-5.

12 Devas MB, Irvine RE. The geriatric orthopaedic unit. British fournal of Geriatric Practice 1969;6: 19-25.

13 Clark ANG, Wainwright D. The management of the fractured neck of femur in the elderly female: a joint approach of orthopaedic surgery and geriatric medicine. Gerontology Clinics 1966;8:321-6. 
14 Boyd RV, Hawthorne J, Wallace WA, Worlock PH, Crompton EH. The Nottingham orthogeriatric unit after 1000 admissions. Injury 1983;15: 193-6

15 Taggart HM. Geriatric-orthopaedic rehabilitation in Belfast In: Caird FI. Evans JG eds. Adoanced geriaric medicine 3. London: Pirman, 1983:144.50.

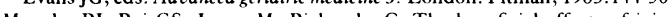
(1987:16:273-8.

17 Smith DL. The elderly in the convalescent orthopaedic trauma ward: can the geriatrician help? Health Bull (Edinb) 1984:42:36-45.

18 Burley LE, Scorgie RE, Currie CT, Smith RG, Williamson J. The joint geriatric orthopaedic service in South Edinburgh. Health Bull (Edinb) $1984 ; 42: 133-40$

19 Fordham R, Thompson R, Holmes J, Hodkinson C. A cost-benefit study of geriatric-orthopaedic management of patients with fractured neck of femur. York: University of York, 1986. (Centre For Health Economics discussion paper 14.

20 Harrington MG, Brennant M, Hodkinson HM. The first year of a geriatricorthopaedic liaison service: an alternative to 'orthogeriatric' units? Age Ageing 1988;17:129-33.

$21 \mathrm{Katz}$ S, Ford AB, Moskowitz RW, Jackson BA, Jaffe MW. Studies of illness in the aged: the index of ADL: a standardized measure of biological and the aged: the index of ADL: a standardized

22 Pfeifer E. A shor porable mental stats que organic brain deficit in elderly patients. $f$ Am Geriatr Soc 1975;23:433-41.
23 Jensen JS, Bagger J. Long term social prognosis after hip fractures. Actu Orthop Scand 1982;53:97-101.

24 Tukey JW. Exploratory data analysis. Reading, Massachusetts: AddisonWesley, 1977 .

25 Pryor GA, Myles JW, Williams DRR, Anand JK. Team management of the elderly patient with hip fracture. Lancet 1988;i:401-3.

26 Department of Health and Social Security. Orthopaedic services: waiting time for out-patient appointments and inpatient treatment. Report of a working party 10 the Secretary of State for Social Services. London: HMSO, 1981

27 Robbins JA, Donaldson LJ. Analysing stages of care in hospital stay for fractured neck of femur. Lancet 1984;ii: 1028-9.

28 Orem DE. Nursing: concepts of practice. New York: McGraw-Hill, 1980

9 Villar RN, Allen SM, Barnes SJ. Hip fractures in healthy patients: operative delay versus prognosis. Br Med f 1986;293:1203-4.

$30 \mathrm{McLaren}$ AD, Stockwell MC, Reid VT. Anaesthetic techniques for surgical correction of fractured neck of femur: a comparative study of spinal and general anaesthesia in the elderly. Anaesthesia 1978;33:10-4.

31 Burnett JW, Gustilo RB, Williams DN, Kind AC. Prophylactic antibiotics in hip fractures: a double-blind, prospective study. F Bone foint Surg [Am] 1980;62:457-62.

32 Wolfe JHN. Postphlebitic syndrome after fractures of the leg. $\mathrm{Br}$ Med $\mathrm{J}$ $1987 ; 295: 1364-5$.

(Accepted 8 September 1988)
Hvidöre Hospital, DK-2930 Klampenborg, Denmark Hans-Henrik Parving, MD, chief physician

Eva Hommel, MD, registrar Ulla M Smidt, laboratory technician

Correspondence to: $\mathrm{Dr}$ Parving.

\title{
Protection of kidney function and decrease in albuminuria by captopril in insulin dependent diabetics with nephropathy
}

\author{
Hans-Henrik Parving, Eva Hommel, Ulla M Smidt
}

\begin{abstract}
Study objective-To assess whether long term inhibition of angiotensin converting enzyme with captopril and frusemide or bendrofluazine protects kidney function in diabetic nephropathy.

Design-Non-randomised controlled before-after trial of matched hypertensive insulin dependent diabetics with nephropathy treated with captopril and frusemide or bendrofluazide.
\end{abstract}

Setting-Outpatient diabetic clinic in tertiary referral centre.

Patients-Treatment group of 18 hypertensive insulin dependent diabetics with nephropathy (mean age 33), who had not been treated previously. Control group of 13 patients (mean age 32 ) fulfilling the same entry criteria from a prospective study

Interventions - Treatment group was given daily captopril $37 \cdot 5-100 \cdot 0 \mathrm{mg}$ and frusemide (mean) $98 \mathrm{mg}$ (10 patients) or bendrofluazide (mean) $4 \mathrm{mg}$ (seven). Treatment was continued for about two and a half years. Controls were not treated.

End point-Measurement of arterial blood pressure, albuminuria, and glomerular filtration

Measurements and main results-Baseline values were identical in treated and untreated groups respectively: mean blood pressure 146/93 (SE 3/1) mm Hg $v$ 137/95 (2/1) mm Hg; geometric mean albuminuria 982 (antilog SE 1.2) $\mu \mathrm{g} / \min v 936(1.2)$ $\mu \mathrm{g} / \mathrm{min}$; and mean glomerular filtration rate 98 (SE 5) $\mathrm{ml} / \mathrm{min} / 1.73 \mathrm{~m}^{2} v 96(6) \mathrm{ml} / \mathrm{min} / 1.73 \mathrm{~m}^{2}$. Mean arterial blood pressure fell by $8.7(1.3) \mathrm{mm} \mathrm{Hg}$ with captopril and rose by $6.6(1.5) \mathrm{mm} \mathrm{Hg}$ in controls, $(\mathrm{p}<0.001)$; Albumin excretion decreased to $390(1 \cdot 1) \mu \mathrm{g} / \mathrm{min}$ with captopril and rose to $1367(1.3) \mu \mathrm{g} / \mathrm{min}$ in controls $(p<0.001)$. The rate of decrease in glomerular filtration rate was lower with captopril $(5.8(0.7)$ $\mathrm{ml} /$ year $v 10.0(1.3) \mathrm{ml} /$ year $)(\mathrm{p}<0.01)$. Rate of fall in glomerular filtration rate and mean arterial blood pressure were significantly correlated $(n=31, r=0.37$, $\mathbf{p}<0.05$ )

Conclusions-Captopril is a valuable new drug for treating hypertension in insulin dependent diabetics with nephropathy.

\section{Introduction}

Renal failure due to diabetic nephropathy is the main cause of death in patients with insulin dependent diabetes, ${ }^{12}$ and on average death occurs seven years after the start of persistent albuminuria. ${ }^{13}$ Increased arterial pressure is an early and common occurrence in diabetic nephropathy. ${ }^{4}$ Systemic hypertension when transmitted to the glomerular capillary network results in glomerular capillary hypertension, ${ }^{5}$ which has also been shown in normotensive rats with diabetes that had been induced by streptozotocin. ${ }^{67} \mathrm{~A}$ link between glomerular hypertension and albuminuria and the development and progression of diabetic glomerulopathy has been suggested. ${ }^{89}$ In rats infusion of angiotensin II induced glomerular hypertension and albuminuria. ${ }^{10}$

We have shown that glomerular filtration rate is not dependent on angiotensin II and that inhibiting angiotensin converting enzyme with captopril for one week reduces albuminuria in hypertensive insulin dependent diabetics with nephropathy. "We present here our findings on the long term effect of captopril on glomerular filtration rate and albuminuria in such patients.

\section{Patients and methods}

\section{PATIENTS}

We examined the records of all patients with insulin dependent diabetes who had proteinuria (those positive on dipstick testing) who were visiting the outpatient clinic at this hospital during 1984. ${ }^{12}$ We invited all hypertensive patients to join the study if they were aged under 50; had persistent albuminuria $(>300 \mathrm{mg}$ albumin/day) and a serum creatinine concentration less than $120 \mu \mathrm{mol} / \mathrm{l}$ and no oedema; and developed diabetes before the age of 31 but were not receiving antihypertensive treatment (including diuretics) and were not blind. Twenty patients fulfilled these criteria and all gave fully informed consent. At the start of the study one patient was excluded because treatment with thiazides had been started for oedema. One man was excluded after nearly one year's investigation because a renal biospy showed mesangioproliferative glomerulonephritis superimposed on a diffuse diabetic glomerulosclerosis.

Eighteen patients were studied. Apart from the first three patients (cases 1-3), who initially received combined treatment with captopril and a diuretic, all the remaining 15 patients were initially included in a randomised controlled trial to investigate the effect of 